\title{
Variations de l'équipement enzymatique de Streptococcus thermophilus
}

\author{
par \\ D. Hemme, Danièle WaHL et Michèle Nardi*
}

\section{INTRODUCTION}

Streptococcus thermophilus est une espèce que l'on trouve normalement associée à un ou plusieurs lactobacilles homofermentaires dans les levains thermophiles utilisés par l'industrie laitière tant dans la fabrication du yoghourt que dans celle des fromages à pâte cuite (Comté, Emmental, Beaufort). A ce titre il joue un rôle déterminant dans la fermentation lactique au cours de la fabrication de ces produits $[1,2,21]$.

S. thermophilus se développe mieux dans le lait chauffé au moins à $90^{\circ} \mathrm{C}$ [3], dans des conditions anaérobies [9]. Il est difficile à cultiver en milieu de laboratoire et ce n'est que récemment que Terzaghi et al. [30] ont décrit le milieu M 17 qui convient à cette espèce. Il est par ailleurs connu que $S$. thermophilus utilise préférentiellement les diholosides (lactose et également saccharose), mais il s'agit là d'observations grossières. Dernièrement, Somkuti et Steinberg [28] ont décrit l'adaptation possible de $S$. thermophilus aux oses (glucose et galactose) mais la méthodologie utilisée (courbes de croissance) est limitée. Très récemment, Hemme et al. [13] ont démontré que les stimulations de $S$. thermophilus observées dans le lait dont le lactose est hydrolysé par une $\beta$-galactosidase industrielle, sont en fait dues à la production in situ de peptides fabriqués par des protéases contaminantes à partir des protéines du lait.

Sur le plan biochimique, très peu de données existent sur S. thermophilus. Ottogalli et al. [24] ont montré l'homogénéité des génômes des souches par hybridation des acides désoxyribonucléiques. Le catabolisme des glucides n'est pas, comme c'est le cas pour les streptocoques mésophiles (voir revues 15 et 16), connu. Les seuls élé-

* Institut National de la Recherche Agronomique (C.N.R.Z.) - 78350 Jouy-en-Josas (France). 
ments sont l'existence d'une $\beta$-galactosidase, démontrée par Wierzbicki et Kosikowski en 1973 [34], confirmée par Rao et Dutta [25] et nousmêmes (publication en cours). Quelques précisions ont été fournies par Rao et Dutta concernant l'induction de la $\beta$-galactosidase [25] et les propriétés de cette enzyme [26]. Somkuti et Steinberg [28] supposent constitutif le système de transport et d'utilisation du lactose, ce qui contredit des éléments fragmentaires non publiés de Reddy et al. [27].

L'objectif du présent travail a donc été de mettre en évidence et d'étudier un certain nombre d'activités enzymatiques caractéristiques de la fermentation lactique chez $S$. thermophilus, d'en apprécier les variations selon les souches et d'étudier l'influence de la phase de croissance, et donc indirectement du $\mathrm{pH}$ du milieu de culture, de la température d'incubation du milieu et de la nature de la source glucidique.

\section{MATERIEL ET METHODES}

\section{Souches bactériennes}

Nous avons utilisé les souches S. thermophilus 302 et 385 de la collection du Centre National de Recherches Zootechniques (CNRZ). La souche 302 présente dans le lait une activité acidifiante qui est assez représentative de celle de la majorité des souches de $S$. thermophilus, alors que la souche 385 présente, elle, des caractères très particuliers [2, 13].

Les souches sont conservées à $-30^{\circ} \mathrm{C}$ sous forme de cultures sur lait (inoculum 5 p. 100) non incubées, de façon à disposer d'un stock de cultures préparées à partir d'une même culture mère et utilisées au fur et à mesure des besoins.

Après décongélation rapide, les cultures étaient incubées $10 \mathrm{~h}$ à $42^{\circ} \mathrm{C}$ et repiquées une fois avant l'utilisation proprement dite.

\section{Préparation des cultures d'essais}

Une culture sur lait de $6 \mathrm{~h}$ (souche 385) ou $12 \mathrm{~h}$ (souche 302) était utilisée pour ensemencer 1,5 1 de milieu M 17 [30] dont la concentration était de $10 \mathrm{~g}$ de lactose par litre. On ajoutait ensuite à cette culture 3,5 1 de milieu M 17 sans sucre préalablement réchauffé à $42^{\circ} \mathrm{C}$. Les 51 résultants étaient répartis à raison de $780 \mathrm{ml}$ dans des flacons de 11 contenant déjà $220 \mathrm{ml}$ d'une solution de sucre (lactose, glucose, galactose ou glucose et galactose) réchauffée à $42^{\circ} \mathrm{C}$ et dont la concentration en sucre était telle que la concentration finale en sucres des cultures de 11 ainsi obtenues était : lactose $10 \mathrm{~g} / 1$; glucose $5 \mathrm{~g} / 1$; galactose $5 \mathrm{~g} / 1$ ou glucose et galactose $5 \mathrm{~g} / 1$ de chaque ose.

Influence de l'âge de la culture : des cultures incubées à $42^{\circ} \mathrm{C}$ et ensemencées avec un même volume d'inoculum provenant de la 
même préculture sont arrêtées lorsque le $\mathrm{pH}$ atteint 6,$1 ; 5,8 ; 5,4$; 5,2 et 5,1 .

Influence de la température de culture: des cultures préparées comme il a été indiqué ci-dessus étaient incubées à $30,42,45,48$ et $51^{\circ} \mathrm{C}$. Le $\mathrm{pH}$ de chaque culture était suivi et lorsque celui-ci atteignait 5,3 , les cultures étaient refroidies rapidement dans un bain d'eau glacée. Dans ces conditions, le pH des cultures était 5,2 après refroidissement.

Influence de la source glucidique : les cultures réalisées avec des inoculums identiques et provenant d'une même culture sur lactose, étaient incubées à $42^{\circ} \mathrm{C}$. Elles contenaient les concentrations en sucres données plus haut. Les cultures étaient arrêtées lorsque le $\mathrm{pH}$ était de 6,0 sauf pour les cultures avec galactose seul qui n'atteignaient jamais 6,0 et étaient donc arrêtées à $\mathrm{pH}$ 6,3. Lors de l'arrêt, les cultures étaient refroidies très vite comme précédemment.

\section{Préparation des extraits bruts cellulaires}

Les bactéries des cultures refroidies étaient récoltées par centrifugation pendant $20 \mathrm{~min}$ à $30000 \mathrm{~g}$ et à $4^{\circ} \mathrm{C}$ (Sorvall). Les culots bactériens obtenus étaient lavés par remise en suspension des cellules à l'aide d'un homogénéisateur (Ultra-Turrax) dans du tampon phosphate de sodium $\mathrm{pH}$ 6,8 $50 \mathrm{mM}$ puis $100 \mathrm{mM}$ au deuxième rinçage. Du culot de centrifugation final, $2 \mathrm{~g}$ de bactéries (poids humide) étaient mis en suspension dans $15 \mathrm{ml}$ de tampon $100 \mathrm{mM}$ et soumis à l'action d'un appareil Vibrogen (Labo-Moderne France), à $4^{\circ} \mathrm{C}$, en présence de billes de verre de diamètre $0,1 \mathrm{~mm}$ et en utilisant le bol de $35 \mathrm{ml}$. Après 12 min d'action, le lysat bactérien obtenu était additionné de $10 \mathrm{ml}$ de tampon $100 \mathrm{mM}$, puis déposé sur un verre frité $\mathrm{n}^{\circ} 2$ et lavé avec le même tampon de telle sorte que le volume final soit de $30 \mathrm{ml}$. Le surnageant ainsi débarrassé des billes de verre était soumis à une centrifugation pendant $20 \mathrm{~min}$ à $30000 \mathrm{~g}$ et à $4^{\circ} \mathrm{C}$. Le surnageant opalescent était récupéré. Il constituait l'extrait brut cellulaire. Les extraits bruts issus des différentes cultures d'une même série d'essais étaient ajustés à la même concentration en protéines, répartis en fractions aliquotes qui étaient stockées à $4^{\circ} \mathrm{C}$ pour une partie et à $-30^{\circ} \mathrm{C}$ pour l'autre partie.

\section{Mesures et dosages}

On mesurait le $\mathrm{pH}$ des cultures avec un $\mathrm{pH}$-mètre Radiometer PHM 64. Les protéines étaient dosées par la méthode de Lowry et al. [17]. Les activités enzymatiques des extraits bruts étaient mesurées cinétiquement avec enregistrement en continu de la vitesse initiale des réactions catalysées, à $420 \mathrm{~nm}$ pour les enzymes $\beta$-galactosidase et phospho- $\beta$-galactosidase et à $340 \mathrm{~nm}$ (lampe UV) pour les autres enzymes révélées à l'aide de dosage faisant appel à l'oxydo-réduction du coenzyme NAD (nicotinamide adénine dinucléotide). On utilisait 
pour cela un spectrophotomètre Beckman UV 25 muni de son enregistreur. Les mesures étaient faites à $30^{\circ} \mathrm{C}$. L'équilibrage de la température des cuves se faisait par un séjour des cuves pendant $10 \mathrm{~min}$ dans le compartiment du spectrophotomètre qui était lui-même thermostaté électriquement. Les cuves plastiques utilisées (Ratiolab) étaient des cuves semi-micro dans lesquelles le volume du mélange réactionnel était $0,65 \mathrm{ml}$. On ajoutait $0,05 \mathrm{ml}$ d'extrait brut à la dilution convenable pour effectuer les dosages. Les mélanges réactionnels étaient dérivés de ceux préconisés par la Société Boehringer-Mannheim. Ils étaient les suivants :

- $\beta$-galactosidase ( $\beta$-gal): orthonitrophényl- $\beta$-D-galactoside (ONPG) $5 \mathrm{mM}$ dans du tampon phosphate de $\mathrm{Na} 50 \mathrm{mM}$ pH 6,5 ;

- phospho- $\beta$-galactosidase (P- $\beta$-gal) : l'ONPG est remplacé par l'ONPG-6-phosphate ;

- hexokinase (HK) : tampon triéthanolamine $44 \mathrm{mM}$ pH 7,6 contenant du glucose $235 \mathrm{mM}$, du $\mathrm{MgCl}_{2} 7 \mathrm{mM}$, du coenzyme NADP (nicotinamide adénine dinucléotide phosphate) 0,44 $\mathrm{mM}$, de l'ATP (adénosine triphosphate) 0,29 $\mathrm{mM}$ et de l'enzyme glucose-6-phosphate déshydrogénase à raison de $494 \mathrm{mU} / \mathrm{ml}$;

- aldolase (Ald) : tampon collidine $55 \mathrm{mM} \mathrm{pH} \mathrm{7,4} \mathrm{contenant} \mathrm{du}$ fructose 1-6-diphosphate $3 \mathrm{mM}$, du monoiodoacétate $0,3 \mathrm{Mm}$, du coenzyme réduit NADH $0,391 \mathrm{mM}$ et les enzymes glycéroldéshydrogénase $(0,25 \mathrm{U} / \mathrm{ml})$, triose-isomérase $(1,7 \mathrm{U} / \mathrm{ml})$ et lacticodéshydrogénase $(0,78 \mathrm{U} / \mathrm{ml})$;

- 3-phosphoglycéraldéhyde déshydrogénase (GAPDH) : tampon triéthanolamine $88 \mathrm{mM}$ pH 7,6 contenant du glycérate-3-phosphate $6,3 \mathrm{mM}$, de l'ATP $0,56 \mathrm{mM}$, du NADH 0,11 mM, de l'EDTA (Ethylène Diamine Tetra Acetic acid, Titriplex III, Merck) 0,91 mM, du $\mathrm{MgSO}_{4}$ $2 \mathrm{mM}$ et l'enzyme phospho-glycérate kinase à raison de $15 \mathrm{U} / \mathrm{ml}$;

- pyruvate kinase (PK) : tampon triéthanolamine $88 \mathrm{mM} \mathrm{pH} \mathrm{7,6}$ contenant du phospho-énolpyruvate 0,56 $\mathrm{mM}$, de l'ADP (adénosine diphosphorique) $0,74 \mathrm{mM}$, du NADH $0,139 \mathrm{mM}$ et l'enzyme lacticodéshydrogénase $(9,3 \mathrm{U} / \mathrm{ml})$;

- L-lacticodéshydrogénase (LDH) : tampon glycine-NaOH $416 \mathrm{mM}$ pH 9,0 contenant de l'hydrazine $333 \mathrm{mM}$, du lactate de $\mathrm{Na} 83 \mathrm{mM}$ et du NAD 2,2 mM.

\section{RESULTATS}

\section{Validité des dosages}

La comparaison d'activités spécifiques dans les différents extraits bruts solubles obtenus devait être rendue possible. Pour cela, des expériences répétées ont été effectuées. Elles concernaient soit le dosage proprement dit des activités enzymatiques, soit l'ensemble des 
manipulations, à partir de cultures différentes. En définissant des conditions de récolte des cellules très draconiennes (voir méthodes), en effectuant les dosages enzymatiques sur les extraits bruts préparés dans des conditions parfaitement identiques, et en diluant les extraits de telle sorte que leur concentration en protéines soit chaque fois $1 \mathrm{mg} / \mathrm{ml}$, les résultats obtenus dans les différents essais peuvent être comparés.

Dans nos conditions expérimentales, les variations obtenues ne dépassaient pas 6 p. 100 pour six activités enzymatiques. Seuls les résultats obtenus pour la 3-phosphoglycéraldéhyde déshydrogénase peuvent varier plus largement $( \pm 16 \mathrm{p} .100)$. On a tenu compte de ce pourcentage d'incertitude dans l'interprétation des résultats.

\section{Activités $\beta$-galactosidase et phospho- $\beta$-galactosidase}

Le tableau 1 montre que les deux souches 302 et 385 ont des activités $\beta$-galactosidase et phospho- $\beta$-galactosidase du même ordre de grandeur. La souche 385 a toutefois une activité $\mathrm{P}-\beta$-gal double de l'activité $\beta$-gal. Cela explique peut-être en partie sa moins bonne croissance dans le lait dont le lactose a été hydrolysé par une $\beta$-galac-

\section{TABLEAU 1}

Activités spécifiques $\beta$-galactosidase et phospho- $\beta$-galactosidase chez Streptococcus thermophilus

\begin{tabular}{|c|c|c|}
\hline \multirow{2}{*}{ Enzymes } & \multicolumn{2}{|c|}{ Activités spécifiques } \\
\hline & souche 302 & souche 385 \\
\hline$\beta$-galactosidase (hydrolyse de l'ONPG) & 4,5 & 2,9 \\
\hline Phospho- $\beta$-galactosidase (mesurée sur ONPG 6-P) & 5,2 & 7,0 \\
\hline
\end{tabular}

Milieu M 17 contenant $10 \mathrm{~g}$ de lactose/l.

Température d'incubation $42^{\circ} \mathrm{C}$.

Les mesures d'activités sont effectuées sur les extraits bruts obtenus par broyage des cellules recueillies lorsque le $\mathrm{pH}$ de la culture atteint 6,0 .

Les unités sont arbitraires (variation de densité optique à $420 \mathrm{~nm}$ pour une même durée). Les activités spécifiques expriment la vitesse initiale de la réaction obtenue par addition de $0,05 \mathrm{ml}$ d'extrait brut contenant $1 \mathrm{mg} / \mathrm{ml}$ de protéines à $0,65 \mathrm{ml}$ d'ONPG $5 \mathrm{mM}$ ou d'ONPG-6-P $5 \mathrm{mM}$ en tampon phosphate de sodium $50 \mathrm{mM}$. 


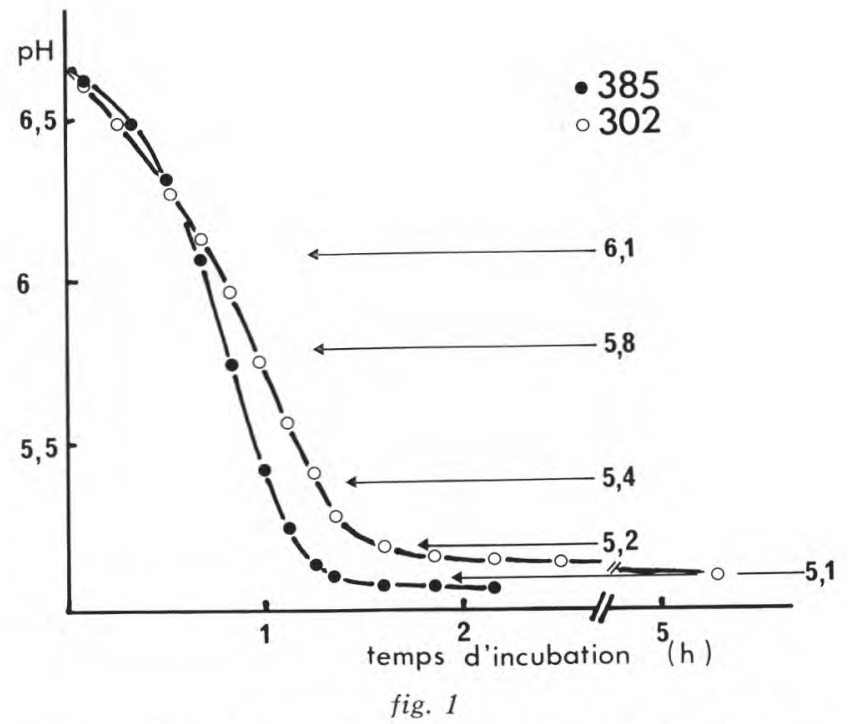

Courbes de croissance de $S$. thermophilus CNRZ 302 et 385 dans le milieu $\mathrm{M} 17$ à $10 \mathrm{~g}$ de lactose $/ 1$ et à $42^{\circ} \mathrm{C}$; ensemencement 1 p. 100 ; production d'acide mesurée par le $\mathrm{pH}$ des cultures.

tosidase [13]. Non seulement l'espèce $S$. thermophilus possède une $\beta$-galactosidase comme cela a déjà été décrit $[34,25]$, mais elle possède aussi, et cela avec une activité spécifique équivalente telle que nous la mesurons sur substrats synthétiques, une activité phospho- $\beta$-galactosidase.

\section{Variation des activités enzymatiques en fonction de la phase de croissance}

Dans le milieu M 17 utilisé et avec une concentration en lactose de $10 \mathrm{~g} / 1$, la souche 385, malgré un léger retard après l'inoculation, abaisse plus vite le $\mathrm{pH}$ du milieu que la souche 302 . La souche 385 conserve donc dans nos conditions sa particularité d'avoir un taux de croissance supérieur à celui des autres souches de $S$. thermophilus. On note de même qu'une fois la phase de ralentissement atteinte, le $\mathrm{pH}$ de la culture de la souche 385 est vers 5,1 alors que celui de la souche 302 n'est qu'à 5,2 . Vu le très fort pouvoir tampon du milieu M 17, cette différence est très significative.

On constate (fig. 2) d'une façon générale que les variations des activités enzymatiques mesurées sont plus importantes, selon le pH auquel sont les cellules, chez la souche 302 que chez la souche 385 , la 


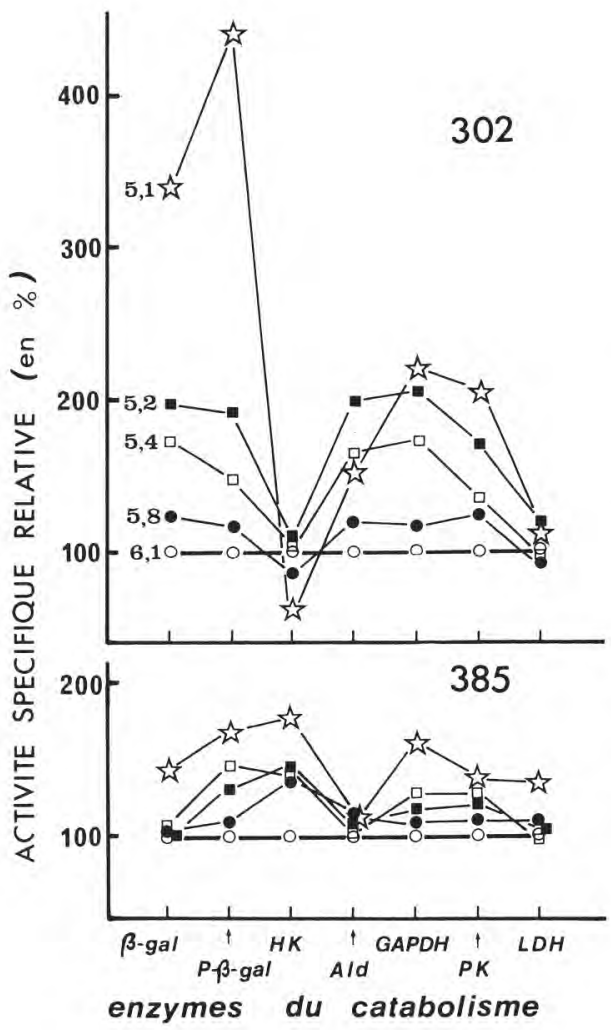

fig. 2

Variations des activités spécifiques relatives de Streptococcus thermophilus 302 et 385 en fonction du $\mathrm{pH}$ d'arrêt de la culture.

Milieu M 17 à $10 \mathrm{~g}$ de lactose $/ 1$; température d'incubation $42^{\circ} \mathrm{C}$; ensemencement 1 p. 100. Les activités enzymatiques mesurées à $\mathrm{pH}$ 6,1 sont prises comme 100 p. 100. Enzymes: $\beta$-galactosidase ( $\beta$-gal), phospho- $\beta$-galactosidase (P$\beta$-gal), hexokinase (HK), aldolase (Ald), 3-phospho-glycéraldéhyde déshydrogénase (GAPDH), pyruvate kinase (PK) et L-lacticodéshydrogénase (LDH).

LDH faisant toutefois exception. Elle est peu soumise à variation tant chez une souche que chez l'autre. De même l'hexokinase varie peu chez la souche 302 alors que c'est l'aldolase qui a toujours la même activité chez la souche 385 .

Les augmentations obtenues pour la souche 302 restent néanmoins régulières mais faibles jusqu'à un $\mathrm{pH}$ compris entre 5,8 et 5,4 . Par contre, à $5,4,5,2$ et à fortiori 5,1 , les augmentations de $\beta$-gal, P- $\beta$-gal, Ald, GAPDH et PK deviennent fortes. Si on se réfère à la figure 1 , ces augmentations fortes interviennent lorsque la culture sort de la phase exponentielle de croissance. Or, c'est également vers $\mathrm{pH} 5,1$ que les activités spécifiques augmentent.

Les faibles variations que présente la $\mathrm{LDH}$ tant chez une souche que chez l'autre sont peut-être en relation avec l'étape en jeu, la réduction du pyruvate en lactate, qui est effectuée par des enzymes dont la 
concentration cellulaire est importante y compris lorsque les conditions sont les plus favorables (phase exponentielle). Si l'activité des autres enzymes, mesurée dans les conditions optimales in vitro, augmente, cela signifie en effet que la concentration cellulaire de ces enzymes a augmenté lorsque le $\mathrm{pH}$ de la culture a diminué.

\section{Variation des activités enzymatiques en fonction de la température de croissance des bactéries}

On trouvera dans le tableau 2 les variations d'activité acidifiante en fonction de la température de croissance pour chaque souche. Si la température optimale de croissance, indiquée ici par le temps le plus faible mis pour atteindre $\mathrm{pH} 5,3$ est de $45^{\circ} \mathrm{C}$ pour les deux souches, la souche 385 est néanmoins plus mésophile que la souche 302 . La différence n'est toutefois pas si importante que celle observée en culture sur lait [2].

\section{TABLEAU 2}

Croissance de $S$. thermophilus à diverses températures

\begin{tabular}{l|c|c|c|c|c}
\hline & \multicolumn{3}{|c}{ Temps de culture pour atteindre pH 5,3 (en min) } \\
$\begin{array}{c}\text { Souches de } \\
\begin{array}{c}\text { Streptococcus } \\
\text { thermophilus }\end{array}\end{array}$ & $30^{\circ} \mathrm{C}$ & $42^{\circ} \mathrm{C}$ & $45^{\circ} \mathrm{C}$ & $48^{\circ} \mathrm{C}$ & $51^{\circ} \mathrm{C}$ \\
\cline { 2 - 4 } & 247 & 108 & 103 & 108 & 133 \\
CNRZ 302 & 185 & 70 & 68 & 88 & 130 \\
CNRZ 385 & & & & & \\
\hline
\end{tabular}

Milieu M 17 contenant $10 \mathrm{~g}$ de lactose par litre. Ensemencement 1 p. 100.

Les variations d'activité des sept enzymes sont données dans la figure 3. C'est surtout l'activité hexokinase qui augmente fortement avec la température d'incubation, mais alors que l'augmentation cesse dès $45^{\circ} \mathrm{C}$ pour la souche 385 , elle double à nouveau pour la souche 302 entre 45 et $51^{\circ} \mathrm{C}$. A $51^{\circ} \mathrm{C}$, la croissance des bactéries est très faible, surtout pour la souche 385, lorsqu'elles sont cultivées dans le lait. L'hexokinase est probablement une des enzymes en cause dans l'arrêt de la croissance par la température et la souche 385 aurait moins de possibilité d'augmenter sa concentration cellulaire en cette enzyme. 

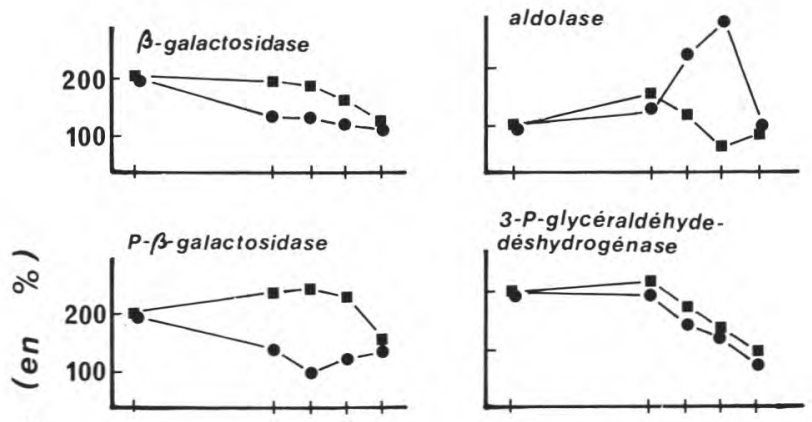

3-P-glycéraldèhyde -

déshydrogénase
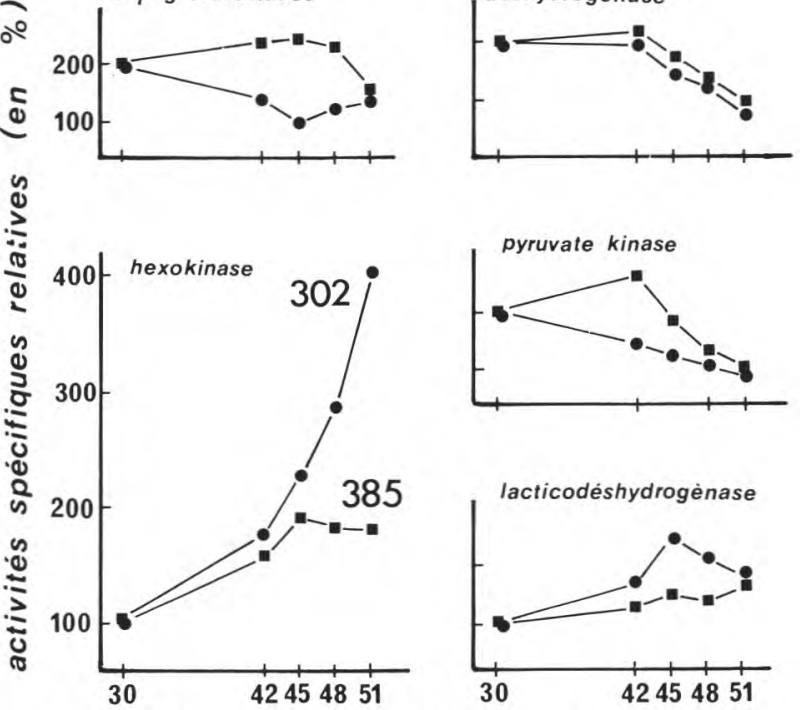

température de croissance $\left(e n{ }^{\circ} \mathrm{C}\right)$

fig. 3

Variations des activités spécifiques relatives de Streptococcus thermophilus suivant la température d'incubation des cultures $(\bullet=302 ;==385)$ en milieu M 17 à $10 \mathrm{~g}$ de lactose $/ 1$.

Pour les enzymes $\beta$-galactosidase et P- $\beta$-galactosidase, les diminutions observées, surtout chez la souche 302 , peuvent laisser penser à une efficacité plus grande de ces enzymes lorsque la température croît. Plus généralement tant ces deux enzymes que GAPDH, PK et LDH sont peu affectées par l'augmentation de la température, ce qui paraît concorder avec le caractère thermophile de $S$. thermophilus. Le phénomène observé pour l'aldolase de la souche 302 peut correspondre toutefois à une augmentation de la concentration cellulaire de l'enzyme entre 42 et $48^{\circ} \mathrm{C}$, pour pallier à une dénaturation thermique partielle mais réversible de telle sorte qu'en dosant l'activité à $30^{\circ} \mathrm{C}$, il y a en apparence augmentation. Par contre, pour $51^{\circ} \mathrm{C}$, la baisse constatée correspond très certainement à une inactivation irréversible de 
l'aldolase. L'aldolase de la souche 385 se comporte très différemment. Au contraire l'activité 3-P-glycéraldéhyde déshydrogénase des deux souches est très comparable.

\section{Influence de la source glucidique sur les activités enzymatiques}

La rapidité de croissance des souches suivant le ou les sucres utilisés est exprimée, dans le tableau 3, par le temps mis par les cultures pour atteindre pH 6 (6,3 dans le cas où la source glucidique est

\section{TABLEAU 3}

Temps d'incubation des cultures de $S$. thermophilus à $42^{\circ} \mathrm{C}$ pour atteindre $\mathrm{pH}$ 6,0 selon la source glucidique du milieu M 17

\begin{tabular}{l|c|c}
\hline & \multicolumn{2}{|c}{ Temps mis par les souches pour atteindre } \\
$\mathrm{pH} \mathrm{6,0}(\mathrm{en} \mathrm{min)}$
\end{tabular}

* $\mathrm{pH} 6,3$ au lieu de 6,0.

le galactose). Dans le milieu M 17 utilisé, le lactose est de loin la meilleure source glucidique. L'écart observé entre la culture d'une souche sur milieu lactosé et la culture de la même souche sur milieu glucosé est plus important pour la souche 385. Il en est de même lorsqu'il y a dans le milieu à la fois du glucose et du galactose. L'acidification est très faible pour les deux souches lorsque le galactose est la seule source, les conditions expérimentales utilisées permettant d'ailleurs une poursuite de la croissance avec le reste de lactose apporté par l'inoculum. 
A l'exception des activités LDH de la souche 302 pour le milieu contenant du glucose ou un mélange des deux oses, toutes les activités enzymatiques mesurées sont plus fortes dans les conditions défavorables à la croissance que lorsque la source glucidique est le lactose (tab. 4).

Bien qu'il n'y ait plus de lactose dans le milieu, les deux souches continuent à synthétiser à la fois la $\beta$-galactosidase et la phospho- $\beta$ galactosidase. La présence de glucose, seul ou en mélange avec le galactose, entraîne un doublement (souche 302) et un triplement (souche 385 ) de la quantité de $\beta$-galactosidase. Notons que l'aldolase de la

\section{TABLEAU 4}

Variations des activités spécifiques relatives de Streptococcus thermophilus 385 et 302 selon la source glucidique du milieu M 17

\begin{tabular}{|c|c|c|c|c|c|}
\hline \multirow[b]{2}{*}{$\begin{array}{l}\text { Activités spécifiques } \\
\text { relatives (en p. 100) }\end{array}$} & \multirow[b]{2}{*}{$\begin{array}{c}\text { Souches } \\
\text { CNRZ }\end{array}$} & \multicolumn{4}{|c|}{ Source glucidique du milieu } \\
\hline & & lactose & glucose & $\begin{array}{c}\text { glucose } \\
+ \\
\text { galac- } \\
\text { tose }\end{array}$ & $\begin{array}{l}\text { galac- } \\
\text { tose }\end{array}$ \\
\hline$\beta$-galactosidase & $\begin{array}{l}385 \\
302\end{array}$ & $\begin{array}{l}100 \\
100\end{array}$ & $\begin{array}{l}303 \\
216\end{array}$ & $\begin{array}{l}326 \\
208\end{array}$ & $\begin{array}{l}226 \\
217\end{array}$ \\
\hline Phospho- $\beta$-galactosidase & $\begin{array}{l}385 \\
302\end{array}$ & $\begin{array}{l}100 \\
100\end{array}$ & $\begin{array}{l}164 \\
214\end{array}$ & $\begin{array}{l}152 \\
193\end{array}$ & $\begin{array}{r}99 \\
247\end{array}$ \\
\hline Hexokinase & $\begin{array}{l}385 \\
302\end{array}$ & $\begin{array}{l}100 \\
100\end{array}$ & $\begin{array}{l}171 \\
150\end{array}$ & $\begin{array}{l}194 \\
167\end{array}$ & $\begin{array}{r}161 \\
78\end{array}$ \\
\hline Aldolase & $\begin{array}{l}385 \\
302\end{array}$ & $\begin{array}{l}100 \\
100\end{array}$ & $\begin{array}{l}111 \\
163\end{array}$ & $\begin{array}{l}101 \\
157\end{array}$ & $\begin{array}{l}142 \\
162\end{array}$ \\
\hline $\begin{array}{l}\text { 3-phosphoglycéraldéhyde } \\
\text { déshydrogénase }\end{array}$ & $\begin{array}{l}385 \\
302\end{array}$ & $\begin{array}{l}100 \\
100\end{array}$ & $\begin{array}{l}168 \\
139\end{array}$ & $\begin{array}{l}160 \\
146\end{array}$ & $\begin{array}{l}157 \\
126\end{array}$ \\
\hline Pyruvate kinase & $\begin{array}{l}385 \\
302\end{array}$ & $\begin{array}{l}100 \\
100\end{array}$ & $\begin{array}{l}132 \\
181\end{array}$ & $\begin{array}{l}122 \\
143\end{array}$ & $\begin{array}{l}132 \\
119\end{array}$ \\
\hline L-lacticodéshydrogénase & $\begin{array}{l}385 \\
302\end{array}$ & $\begin{array}{l}100 \\
100\end{array}$ & $\begin{array}{r}131 \\
97\end{array}$ & $\begin{array}{r}121 \\
94\end{array}$ & $\begin{array}{l}177 \\
151\end{array}$ \\
\hline
\end{tabular}

Température d'incubation des cultures : $42^{\circ} \mathrm{C}$; ensemencement 1 p. 100 ; arrêt de la culture à $\mathrm{pH}$ 6,0 (sauf pour les cultures avec galactose : 6,3). Concentrations en sucres utilisées : lactose $10 \mathrm{~g} / 1$; glucose $5 \mathrm{~g} / 1$; glucose + galactose : chaque ose $5 \mathrm{~g} / 1$; galactose $5 \mathrm{~g} / \mathrm{l}$. 
souche 385 reste identique dans ces mêmes conditions, contrairement à celle de la souche 302 qui augmente.

Le transfert des cellules du milieu M 17 contenant du lactose, en milieu M 17 contenant un ose en théorie plus accessible, entraîne en réalité une mauvaise croissance. Celle-ci pourrait en partie être expliquée par les perturbations qu'entraîne le changement de la source glucidique au niveau de la synthèse accrue d'enzymes pourtant devenues inutiles à la bactérie.

\section{DISCUSSION}

Lorsque les bactéries se développent en libérant dans le milieu de culture l'acide lactique qui entraîne une baisse de $\mathrm{pH}$, les bactéries doivent, au moins lorsque le $\mathrm{pH}$ baisse au-dessous d'une certaine valeur, s'adapter au $\mathrm{pH}$. Nos observations le confirment, et on peut conclure que cette adaptation est franchement marquée lorsque le $\mathrm{pH}$ atteint une valeur supérieure de 0,5 unité au $\mathrm{pH}$ final de la culture. Harvey [12] décrivait l'action du $\mathrm{pH}$ chez $S$. lactis, et nos résultats montrent également que le bas $\mathrm{pH}$ doit probablement inhiber partiellement certaines enzymes du métabolisme. Si la souche 385 est capable d'acidifier le milieu plus que ne le fait la souche 302 , c'est probablement qu'elle possède un système plus efficace qui lui permet de garder un $\mathrm{pH}$ intracellulaire favorable à son métabolisme, à un $\mathrm{pH}$ du milieu plus bas que celui auquel le système de la souche 302 perd son efficacité. Le pH entraîne en effet des changements dans les systèmes de perméation, comme cela a été montré chez $S$. faecalis [18] et signalé chez $S$, thermophilus [28].

On peut supposer que si le $\mathrm{pH}$ intracellulaire baisse, les enzymes deviennent moins actives. Les bactéries doivent donc lutter en synthétisant une quantité plus importante d'enzymes. Celles-ci, simplement inactivées par le pH ou d'autres modifications intracellulaires [291, retrouvent leur activité lors des dosages, effectués au pH optimal. Ce sont les seules façons d'expliquer les augmentations d'activités observées. Pour appuyer cette hypothèse, on peut ajouter que, par exemple, les $\beta$-galactosidases et P- $\beta$-galactosidases de $S$. thermophilus ont des $\mathrm{pH}$ optima d'action qui sont respectivement de 8,3 et 7,6 (Hemme et al., en cours de publication). Ces enzymes ont tout lieu d'être fortement inhibées lorsque le $\mathrm{pH}$ atteint 5,5 dans la cellule.

L'activité hexokinase, mesurée in vitro, est constante chez la souche 302. Cela expliquerait, selon le même raisonnement, que cette souche cultive moins vite que la souche 385 à bas $\mathrm{pH}$. L'hexokinase serait ainsi une étape limitante du métabolisme à bas $\mathrm{pH}$ chez la souche 302 , mais non chez la souche 385 . Il serait d'ailleurs intéressant de compléter les résultats de cette étude avec des mesures du nombre de cellules, car il se peut, comme les auteurs néo-zélandais l'ont 
montré chez les streptocoques mésophiles, qu'il y ait arrêt de la croissance avant arrêt de la production d'acide lactique [33].

Contrairement aux streptocoques mésophiles $[20,10), S$. thermophilus cultive mieux lorsque le milieu contient du lactose que lorsqu'il contient du glucose ou du galactose $[6,28]$. Cela est vrai lorsque le milieu est un milieu de laboratoire comme le M 17, ou du lait. Au mieux, certaines souches peuvent utiliser aussi bien le glucose que le lactose. Les cas décrits comme des stimulations de S. thermophilus résultant de l'hydrolyse du lactose du lait [23] résultent en fait d'autres phénomènes qui ont été très récemment élucidés [13]. L'utilisation aussi bonne du glucose que du lactose dans le lait provient certainement de la présence d'autres constituants du lait, différents de ceux des milieux de culture et auxquels $S$. thermophilus est très sensible $[1,3,7]$.

Contrairement à ce qui a été décrit pour de nombreux organismes, $[11,16,18]$, il n'y aurait donc pas, chez $S$. thermophilus, le phénomène d'inhibition catabolique au profit de la source de carbone la plus accessible. Le glucose réprimant la synthèse de la galactokinase (voie de Leloir) ou des enzymes de la voie du tagatose-6-phosphate [4] de telles enzymes doivent probablement être présentes chez $S$. thermophilus puisqu'une phospho- $\beta$-galactosidase est détectée. Nos résultats montrent qu'effectivement le glucose ne réprime pas la synthèse d'enzymes devenues inutiles, mais que bien au contraire, il entraîne une synthèse accrue des enzymes d'utilisation du lactose. En quelque sorte, $S$. thermophilus exige le lactose en milieu M 17 et non les sucres constitutifs de cet ose. La présence simultanée des deux activités $\beta$-galactosidase et phospho- $\beta$-galactosidase laisse penser que les voies d'attaque du lactose sont très certainement différentes de celles des lactobacilles (classique avec une $\beta$-galactosidase) ou celle des streptocoques lactiques ou non lactiques, mésophiles (utilisant une phospho- $\beta$-galactosidase) (voir la revue 16), à l'exception de quelques souches $[5,8$, in 32$]$.

Si $S$. thermophilus phosphoryle le lactose, au moins en partie, le phospho-énolpyruvate (PEP) intervient certainement, notamment dans l'entrée du lactose dans les cellules $[19,22]$. La pyruvate kinase intervient dans la formation de ce composé (PEP). L'augmentation d'environ 50 p. 100 observée chez $S$. thermophilus lorsque le glucose remplace le lactose comme source glucidique peut correspondre aux observations des auteurs néo-zélandais $[31,32,16]$ relatives à l'importance de la pyruvate kinase chez S. lactis. Notons toutefois que cette augmentation d'activité, telle qu'elle est mesurée in vitro, pourrait ne pas rendre compte de l'activité in vivo. Selon ces auteurs, les composés phosphorylés cellulaires jouent un grand rôle d'activation de la pyruvate kinase. Mais nous avons détecté l'enzyme hexokinase, inductible à bas $\mathrm{pH}$, et elle devrait donc pouvoir phosphoryler le glucose exogène en glucose-6-phosphate et permettre le développement des bactéries. Le développement étant faible, cette étape de 
phosphorylation pourrait être limitante. Toutefois, dans ces conditions, les systèmes de régulations de la $\beta$-galactosidase et de la P- $\beta$-galactosidase sont perturbés, peut-être sous l'influence du PEP et par là de la pyruvate kinase. Si la pyruvate kinase ne joue pas chez $S$. thermophilus un rôle équivalent à celui joué chez $S$. lactis, il serait intéressant de comparer ses propriétés d'activation par les substrats phosphorylés.

Le glucose libre pourrait également pénétrer difficilement dans les cellules et la croissance serait limitée par manque de substrat. Peut-être le glucose doit-il être phosphorylé, mais par les mêmes enzymes que celles utilisées par $S$. thermophilus pour phosphoryler le lactose ? Cela signifierait qu'habituellement, le lactose est phosphorylé en lactose diphosphate pour donner du galactose-6-phosphate et du glucose-6-phosphate comme le suggèrent récemment Thompson et Thomas pour $S$. lactis $[32,16]$. Le rejet du galactose dans le milieu, tel que l'ont signalé O'Leary et Woychik [23] pour S. thermophilus permet de s'orienter pour cette espèce vers une autre voie d'utilisation du lactose dans laquelle le lactose serait certes phosphorylé mais en galactose-glucose-6-phosphate. Après action de la $\beta$-galactosidase, il y aurait libération de galactose et de glucose-6-phosphate. Dans ces conditions, l'activité P- $\beta$-galactosidase détectée chez $S$. thermophilus ne serait qu'une enzyme synthétisée gratuitement par les organismes ou bien elle serait une activité secondaire de la $\beta$-galactosidase sur le substrat synthétique ONPG-6-phosphate. Des purifications de la $\beta$-galactosidase nous ont en effet montré (Hemme et al.y publication en cours) que les deux activités décelées sur ONPG et ONPG-6-P pourraient bien être dues à une même enzyme, qui est effectivement une $\beta$-galactosidase dans la mesure oú elle hydrolyse le lactose. Dans l'hypothèse où le glucose serait phosphorylé, on peut supposer que les systèmes de phosphorylation en jeu pour le lactose peuvent subsister pour le glucose, la $\beta$-galactosidase étant régulée parallèlement à ces systèmes ou continuant à être synthétisée, peut-être d'une façon constitutive, lorsque la source glucidique est le glucose. On pourrait ainsi proposer le schéma suivant, d'utilisation des sucres chez $S$. thermophilus (fig 4).

Il serait intéressant de connaître les variations des activités enzymatiques des souches étudiées ici lorsque celles-ci se développent dans le lait. En effet, les différences entre la souche 302, qui peut être considérée comme représentative de l'espèce $S$. thermophilus, et la souche 385 , sont plus importantes en culture sur lait qu'en culture sur milieu M 17 (vitesse de croissance, caractère thermophile,...). Il semblerait, d'après les résultats rapportés ici, que les caractères particuliers de la souche 385 soient en grande partie dus à un potentiel intracellulaire enzymatique moins ou peu sensible aux variations de l'environnement $(\mathrm{pH}$, température). Cette non-sensibilité traduit peut-être une rusticité qui défavorise la souche lorsqu'un facteur, comme la source glucidique, change. Ces remarques mises à part, on doit observer que 


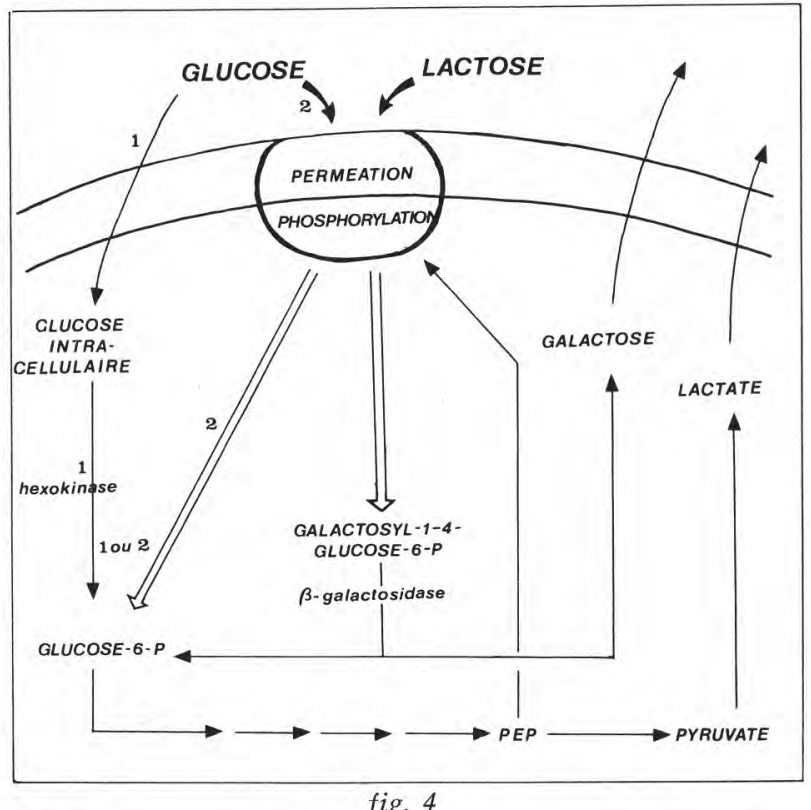

Voies d'utilisation possibles chez Streptococcus thermophilus (voir les explications du texte).

la souche 385 montre une parfaite adaptation au lait, qui ne contient pas de glucose. Dans ce milieu, nous avons d'ailleurs montré qu'elle pouvait être inhibée par l'hydrolyse du lactose dans une certaine proportion [13]. Par contre cette souche bien adaptée possède une capacité de production d'acide dans le lait qui est toujours supérieure à celle qui peut être obtenue par d'autres souches de $S$. thermophilus, même si cette production d'acide est stimulée par addition au lait de substances activantes, tels des extraits de lactobacilles [14].

\section{Remerciements}

Nous remercions J.P. Accolas et M. Desmazeaud pour leurs critiques et suggestions lors de la rédaction du manuscrit.

\section{Ré s u m é}

On sait que Streptococcus thermophilus est différent des streptocoques mésophiles par son caractère thermophile, le fait que cette espèce n'appartient pas au groupe sérologique $\mathrm{N}$ et qu'elle métabolise plutôt les diholosides que les oses. Cette étude apporte des éléments sur le métabolisme glucidique chez $S$. thermophilus. 
S. thermophilus possède à la fois une activité $\beta$-galactosidase (de même que les lactobacilles) et une activité phospho- $\beta$-galactosidase (de même que les streptocoques mésophiles). Les valeurs obtenues pour ces deux activités dans les cellules sont similaires chez la souche 302 représentative de l'espèce. L'activité $\mathrm{P}$ - $\beta$-gal est plus forte que l'activité $\beta$-gal chez la souche 385 connue pour ses particularités. Cinq autres activités enzymatiques ont été mesurées : hexokinase, aldolase, 3-phosphoglycéraldéhyde déshydrogénase, pyruvate kinase et L-lacticodéshydrogénase. Toutes les activités enzymatiques augmentent lorsque le $\mathrm{pH}$ de la culture diminue. Cela est surtout le cas à partir de $\mathrm{pH} 5,2$. L'effet de la température d'incubation de la culture (entre 30 et $51^{\circ} \mathrm{C}$ ) varie selon les enzymes. Toutefois, l'activité hexokinase augmente avec l'augmentation de la température. Enfin, lorsque la source glucidique est défavorable à la croissance (glucose, ou galactose, ou galactose et glucose), la plupart des activités enzymatiques augmentent.

Ces observations permettent de formuler des hypothèses sur le métabolisme glucidique chez $S$. thermophilus et ses régulations, qui sont discutées. Elles montrent qu'il est inopportun, comme certaines revues récentes anglo-saxonnes le laissent supposer, d'assimiler $S$. thermophilus aux espèces de streptocoques mésophiles.

Les particularités de la souche 385 , d'origine japonaise, se retrouvent dans le métabolisme glucidique de cette souche. Les variations des activités enzymatiques sont beaucoup plus limitées chez cette souche que celles trouvées pour la souche 302, représentative de l'espèce. Cette souche 385 , dont les enzymes paraissent constitutives, est une exception qui pourrait être intéressante dans l'industrie laitière,

\section{Su m mary}

VARIATIONS OF ENZYMES SYSTEMS BY STREPTOCOCCUS

THERMOPHILUS

It is well known that Streptococcus thermophilus differs from mesophilic streptococci by the fact that it grows at higher temperatures, it does not belong to the serological $\mathrm{N}$ group and that it metabolises diholosides rather than oses. The present study concerns the carbohydrate metabolism of $S$. thermophilus.

This organism possesses both a $\beta$-galactosidase activity (like lactobacilli) and a phospho- $\beta$-galactosidase activity (like mesophilic streptococci). The values of these two activities in the cells are similar. Five other activities have been evaluated : hexokinase, aldolase, 3-phosphoglyceraldehyde dehydrogenase, pyruvate kinase and L-lactatdehydrogenase. All these activities increase when the $\mathrm{pH}$ of the culture decreases. This is specially the case below $\mathrm{pH} 5,2$. The effect of the 
temperature of incubation of the culture (between $30^{\circ} \mathrm{C}$ and $51^{\circ} \mathrm{C}$ ) varies with the enzymes. However the hexokinase activity increases with the temperature. Finally, when the glucidic source is not favorable for growth (glucose, galactose, or glucose + galactose) most of the enzymatic activities increase.

Various hypotheses on the sugar metabolism in S. thermophilus and its regulation are discussed. It seems unsuitable to assimilate $S$. thermophilus with mesophilic streptococci, as certain recent anglosaxon publications propose.

The strain 385, different from other strains of $S$. thermophilus, has also a metabolism of carbohydrates with peculiar characteristics. The variations of the enzymatic activities are more limited in this strain than those found in strain 302 which can be considered as representative of many strains of $S$. thermophilus. This strain 385, whose enzymes seem to be constitutive, is an exception that can be interesting for the dairy industry.

\section{Zusammenfassung}

Es ist bekannt, daß sich Streptococcus thermophilus von mesophilen Streptokokken durch seine thermophile Eigenschaft unterscheidet und dadurch, da $\beta$ diese Art nicht zur Gruppe $\mathrm{N}$ gehört und bevorzugt Diholosiden metabolisiert. Diese Untersuchung liefert Erkenntnisse über den Zuckermetabolismus bei dieser Art.

$S$. thermophilus enthält sowohl eine $\beta$-Galaktosidaseaktivität (wie die Laktobazillen) als auch eine Phospho- $\beta$-Galaktosidaseaktivität (wie die mesophilen Streptokokken). Die spezifische Aktivität dieser beiden Enzyme in den Zellen ist fast gleich. Es wurden 5 andere Enzymaktivitäten gemessen: Hexokinase, Aldolase, 3-Phosphoglyceraldehydedehydrogenase, Pyruvatkinase und L-Laktatdehydrogenase. Für alle diese Enzymaktivitäten gilt: sie wird um so größer je kleiner der $\mathrm{pH}$-Wert der Kultur wird. Das trifft insbesondere ab pH 5,2 zu. Der Einflup der Kulturbebrütungstemperatur (zwischen $30^{\circ} \mathrm{C}$ und $51^{\circ} \mathrm{C}$ ) variiert je nach Enzym. Die Hexokinaseaktivität nimmt jedoch mit der Temperatur zu. Wenn schließlich die Zuckerquelle das Wachstum nicht mehr begünstigt (Glukose oder Galaktose oder Glukose und Galaktose) nehmen die meisten Enzymaktivitäten zu.

Durch diese Beobachtungen ist es möglich, Hypothesen über den Metabolismus von $S$. thermophilus und seine Regulationsmechanismen aufzustellen, sie werden in dieser Untersuchung diskutiert. Sie zeigen, da $\beta$ es unangebracht ist, wie man es aufgrund einiger neuerer anglosächsischen übersichten (Revues) annehmen könnte, S. thermophilus den mesophilen Streptokokken zuzuordnen. Die besonderen Eigenschaften des Stammes 385, japanischer Herkunft, finden sich im 
Zuckermetabolismus dieses Stammes wieder. Die Enzymaktivitätsvariationen sind für diesen Stamm viel begrenzter als die des Stammes 302, welche als repräsentativ für zahlreiche $S$. thermophilus Stämme angesehen werden kann. Dieser Stamm 385, dessen Enzyme beständig $\mathrm{zu}$ sein scheinen, ist eine interessante Ausnahme.

Reçu pour publication en février 1980

\section{Bibliographie}

[1] Accolas (J. P.), Veaux (M.) et Auclair (J.) (1971), - Etude des interactions entre diverses bactéries lactiques thermophiles et mésophiles, en relation avec la fabrication des fromages à pâte cuite. Le Lait, 51, 249-272.

[2] Accolas (J. P.), Bloquel (R.), Didienne (R.) et Régnier (J.) (1977). - Propriétés acidifiantes des bactéries lactiques thermophiles en relation avec la fabrication du yoghourt. Le Lait, 57, 1-23.

[3] Auclair (J.) et Portmann (A.) (1955). - Influence du chauffage du lait sur le développement des bactéries. I. Croissance des bactéries lactiques dans des laits chauffés à des températures variables. Ann. Technol. agric., 4, 121-131.

[4] Bisset (D. L.) and Anderson (C. L.) (1974). - Lactose and D-galactose metabolism in group $\mathrm{N}$ Streptococci: presence of enzymes for both the Dgalactose-1-phosphate and D-tagatose-6-phosphate pathways. J. Bacteriol., $117,318-320$

[5] Citti (J. E.), SAndine (W. E.) and Elliker (P. R.) (1965). - $\beta$-galactosidase of Streptococcus lactis. J. Bacteriol., 89, 937-942.

[6] Deibel (R. H.) and Seeley (H. W.) Jr, - Streptococcus. In Bergey's Manual of determinative bacteriology, R.E. Buchanian and N.E. Gibbons, Ed., Williams and Wilkins Co, Baltimore, 8th ed., 490-509.

[7] Desmazeaud (M.) et Devoyod (J. J.) (1970). - Action stimulante des microcoques caséolytiques sur les bactéries lactiques thermophiles. Mise en évidence de la nature peptidique des substances stimulantes. Ann. Biol. anim. Bioch. Biophys., 10, 413-430.

[8] Farrow (J.A. E.) and Garvie (E. I.) (1979). - Strains of Streptococcus lactis which contain $\beta$-galactosidase. J. Dairy Res., 46, 121-125.

[9] Galesloot (T. E.), Hassing (F.) and Veringa (H. A.) (1968). - Symbiosis in yoghurt. I. Stimulation of Lactobacillus bulgaricus by a factor produced by Streptococcus thermophilus. Neth. Milk Dairy I., 22, 50-63.

[10] Gilliland (S. E.), SPeck (M. L.) and Woodard (J. R.) (1972), - Stimulation of lactic streptococci in milk by $\beta$-galactosidase. Appl. Microbiol., 23, 21.

[11] HaRvey (R. J.) and Collins (E. B.) (1963). - Role of citrate and acetoin in the metabolism of Streptococcus diacetylactis. J. Bacteriol., 87, 1301.

[12] HaRvey (R. J.) (1965). - Damage to Streptococcus lactis resulting from growth at low pH. J. Bacteriol., 90, 1330-1336.

[13] Hemme (D.), Vassal (L.), Foyen (H.) et Auclair (J.) (1979). - Effet de l'addition de lactase au lait sur le développement des lactobacilles et des streptocoques thermophiles. Le Lait, 59, 597-614.

[14] Hemme (D.), Schmal (V.) and Auclair (J.) (1980). - Effect of the addition of extracts of thermophilic lactobacilli on acid production by Streptococcus thermophilus in milk. J. Dairy Res. (sous presse).

[15] LAW (B. A.) and SHARPE (M. E.) (1978). - Streptococci in the dairy industry. In Streptococci, F. A. Skinner and L. B. Quesnel, Ed., Academic Press, London, 263-278. 
[16] LaWrence (R. C.) and Thomas (T. D.) (1979). - The fermentation of milk by lactic acid bacteria. 29e Symp. Soc. Gen. Microbiol. In Microbial technology: current state, future prospects, A.T. Bull, D.C. Ellwood and C. Ratledge, Ed., Cambridge University Press, London.

[17] Lowry (O. H.), Rosebrough (N. J.), FarR (A. L.) and Randall (R. J.) (1951). Protein measurement with the Folin phenol reagent. J. Biol. Chem., 193, 265-275.

[18] Mc Ginnis (J. G.) and Patgen (K.) (1969), - Catabolite inhibition: a general phenomenon in the control of carbohydrate utilization. J. Bacteriol., 100, 902-913.

[19] Mc Kay (L. L.), Walter (A.), Sandine (W. E.) and Elliker (P. R.) (1969). Involvment of phosphoenol pyruvate in lactose utilization by group $\mathrm{N}$ streptococci. J. Bacteriol., 99, 603-610.

[20] Mc Kay (L. L.), Sandine (W.E.) and EllikeR (P. R.) (1971). - Mechanisms of lactose utilization by lactic acid bacteria: a review. Dairy Sci. Abstracts, $33,493-499$.

[21] Mocouot (G.) (1979). - Swiss-type cheese. J. Dairy Res., 46, 133-160.

[22] Molskness (T. A.), Lee (D. R.), Sandine (W. E.) and Elliker (P. R.) (1973). $\beta$-D-phosphogalactoside galactohydrolase of lactic streptococci. Appl. Microbiol., 25, 373.

[23] O'LeARY (V.S.) and WoYchik (J. H.) (1976). - Utilization of lactose, glucose and galactose by a mixed culture of Streptococcus thermophilus and Lactobacillus bulgaricus in milk treated with lactase enzyme. Appl. Environ. Microbiol., 32, 89-94.

[24] Otrogalli (G.), Galli (A.) and Dellaglio (F.) (1979). - Taxonomic relationships between Streptococcus thermophilus and other streptococci. J. Dairy Res., 46, 127-131.

[25] RAo (M. V.R.) and DutTA (S. M.) (1977). - Production of $\beta$-galactosidase from Streptococcus thermophilus grown in whey. Appl. Environ. Microbiol., 34, 185-188.

[26] RAo (M. V. R.) and DutTA (S. M.) (1979). - An active betagalactosidase preparation from Streptococcus thermophilus. Indian J. Dairy Sci., 32.

[27] Reddy (M. S.), Williams (F. D.) and Reinbold (G. W.) (1973). - Lactose transport in Streptococcus thermophilus. Communic. ADSA M 58, J. Dairy Sci., 56, 634-635.

[28] Somkuti (G. A.) and Steinberg (D. H.) (1979). - Adaptability of Streptococcus thermophilus to lactose, glucose and galactose. J. Food Protection, 42, 885-887.

[29] SWITzer (R. L.) (1977). - The inactivation of microbial enzymes in vivo. Ann. Rev. Microbiol., 31, 135-157.

[30] Terzaghi (B. E.) and Sandine (W. E.) (1975). - Improved medium for lactic streptococci and their bacteriophages, Appl. Microbiol., 29, 807-813.

[31] Thomas (T. D.) (1976). - Activator specificity of pyruvate kinase from lactic streptococci. J. Bacteriol., 125, 1240-1242.

[32] Thompson (J.) and Thomas (T. D.) (1977). - Phosphoenolpyruvate and 2 phosphoglycerate: endogenous energy source(s) for sugar accumulation by starved cells of Streptococcus lactis. J. Bacteriol., 130, 583-595.

[33] TURner (K. W.) and Thomas (T.D.) (1975). - Uncoupling of growth and acid production in lactic streptococci. J. Dairy Sci. Technol., 10, 162-167.

[34] WIERZBicki (L. E.) and KosikowsKi (F. V.) (1973). - Lactase potiential of various microorganisms grown in whey. J. Dairy Sci., 56, 26-32. 